Research Paper

\title{
Transdifferentiation of Human Umbilical Cord-Derived Mesenchymal Stem Cells in Dopaminergic Neurons in a Three-Dimensional Culture
}

\author{
Ardeshir Moayeri $^{1}$ (D), Rafieh Alizadeh ${ }^{2}$ (D), Hatef Ghasemi Hamidabadi ${ }^{* *}$ (D), Maryam Nazm Bojnordi ${ }^{3}$ (D), Ali Niapour ${ }^{4}$, Azim Hedayatpour ${ }^{5}$ (D), \\ Marzieh Darvishi $^{1}$ (D) Fatemeh Heidari $^{6}$ (D), Maryam Soleimani ${ }^{7}$ (D), Leila Elyasi ${ }^{8}$ (D) \\ 1. Department of Anatomy, School of Medicine, Ilam University of Medical Sciences, Ilam, Iran. \\ 2. ENT and Head and Neck Research Center and Department, The Five Senses Health Institute, School of Medicine, Iran University of Medical \\ Sciences, Tehran, Iran. \\ 3. Department of Anatomy \& Cell Biology, Immunogenetic Research Center, School of Medicine, Mazandaran University of Medical Sciences, Sari, Iran. \\ 4. Department of Anatomical Sciences, Research Laboratory for Embryology and Stem Cells, School of Medicine, Ardabil University of \\ Medical Sciences, Ardabil, Iran. \\ 5. Department of Anatomy, School of Medicine, University of Tehran, Tehran, Iran. \\ 6. Department of Anatomy, School of Medicine, Qom University of Medical Sciences, Qom, Iran. \\ 7. Department of Basic Sciences, School of Rehabilitation Sciences, University of Social Welfare and Rehabilitation Sciences, Tehran, Iran \\ 8. Department of Anatomy, Neuroscience Research Center, School of Medicine, Golestan University of Medical Sciences, Gorgan, Iran.
}

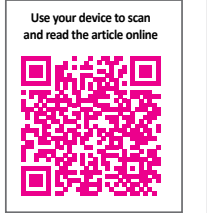

Citation Moayeri, A., Alizadeh, R., Ghasemi Hamidabadi, H., Nazm Bojnordi, M., Niapour, A., Hedayatpour, A., et al. (2022). Transdifferentiation of Human Umbilical Cord-Derived Mesenchymal Stem Cells in Dopaminergic Neurons in a Three-Dimensional Culture. Basic and Clinical Neuroscience, 13(5), 625-636. http://dx.doi.org/10.32598/bcn.2021.973.3

doijhttp://dx.doi.org/10.32598/ben.2021.973.3

\section{(c) (1) (\$)}

Article info:

Received: 27 Jul 2020

First Revision: 03 Mar 2021

Accepted: 07 Aug 2021

Available Online: 01 Sep 2022

Keywords:

Differentiation, Dopaminergic neurons, Human umbilical cord mesenchymal stem cells, In vitro

\begin{abstract}
ABS T RA C T
Introduction: The induction of human umbilical cord-derived mesenchymal stem cells (HUC-MSCs) toward dopaminergic neurons is a major challenge in tissue engineering and experimental and clinical treatments of various neurodegenerative diseases, including Parkinson disease. This study aims to differentiate HUC-MSCs into dopaminergic neuron-like cells.

Methods: Following the isolation and characterization of HUC-MSCs, they were transferred to Matrigel-coated plates and incubated with a cocktail of dopaminergic neuronal differentiation factors. The capacity of differentiation into dopaminergic neuronlike cells in 2-dimensional culture and on Matrigel was assessed by real-time polymerase chain reaction, immunocytochemistry, and high-performance liquid chromatography.

Results: Our results showed that dopaminergic neuronal markers' transcript and protein levels were significantly increased on the Matrigel differentiated cells compared to 2D culture plates.

Conclusion: Overall, the results of this study suggest that HUC-MSCs can successfully differentiate toward dopaminergic neuron-like cells on Matrigel, having great potential for the treatment of dopaminergic neuron-related diseases.
\end{abstract}

* Corresponding Author:

Address: Department of Anatomy \& Cell Biology, Immunogenetic Research Center, School of Medicine, Mazandaran University of Medical Sciences, Sari, Iran. Tel: +98 (11) 335430813

E-mail: hatefdr@gmail.com 


\section{Highlights}

- Dopaminergic neuronal markers were significantly increased on the 3D culture compared to 2D culture plates.

\section{Plain Language Summary}

Stem Cells which derived from Human Umbilical Cord have different potential properties and they may differentiate to other cells such as neuron and dopaminergic neurons. These cells could be used for treatments of various neurodegenerative diseases, including Parkinson disease. In this project, at first, we isolated Human Umbilical Cord cells and harvested in 3D culture plate and incubated with a cocktail of dopaminergic neuronal differentiation factors. Our results showed that dopaminergic neurons were seen in $3 \mathrm{D}$ culture plate compared to $2 \mathrm{D}$ culture plate. Overall, the results of this study suggest that Human Umbilical Cord stem cells can successfully differentiate toward dopaminergic neuron on 3D culture plate, having great potential for the treatment of Parkinson disease.

\section{Introduction}

arkinson disease (PD) is a neurodegen$\mathbf{P}$ erative disorder that is characterized by akinesia, stiffness, movement dysfunction, and resting tremor ( $\mathrm{Lu}$ et al., 2014). The major adverse change of PD is the loss of dopaminergic neurons in the substantia nigra because of oxidative stress (Mehraein et al., 2016; Nutt \& Wooten, 2005; Tavakol et al., 2019). Many studies have reported the promising results of stem-cell-based therapy in PD (Allam et al., 2005; Chu et al., 2015). Following these initial studies, the stem-cell-based treatment was applied to clinical trials for PD patients (Politis \& Lindvall, 2012). Some studies demonstrate the useful effects of stem-cell-derived dopaminergic neurons for PD treatment (Alizadeh et al., 2013; Kawasaki et al., 2000; Kriks et al., 2011). Dopamine neurons were derived from various stem cells, such as embryonic stem cells (Yang, Zhang et al., 2008), human exfoliated deciduous teeth stem cells (Wang et al., 2010), and Wharton's jelly mesenchymal stem cells (Paldino et al., 2014).

Human umbilical cord-derived mesenchymal stem cells (HUC-MSCs) are differentiated into 3 germ layers. As a result, this type of stem cell has received greater attention in regenerative medicine (Cao et al., 2017). HUC-MSCs can be isolated from different parts of the umbilical cord, including vessels, Wharton's jelly, and perivascular regions (Bojnordi et al., 2018; Bongso \& Fong, 2013). The use of HUC-MSCs for the treatment of neurodegenerative diseases in pre-clinical and experimental studies has been widely recognized, chiefly because of their noticeable advantages, such as immunomodulatory effects, differentiation into neural cells, and convenient harvesting by noninvasive methods (Ha- ratizadeh et al., 2016; Tanna \& Sachan, 2014). Transplantation of HUC-MSCs to animal models of ischemic stroke has shown neuroprotective effects by improving neurobehavioral function and decreasing infarct volume (Koh et al., 2008). Studies have also shown that HUCMSCs could be differentiated into neuronal cells after 3 weeks by transferring Lmx $1 \alpha$ and NTN genes to HUCMSCs (Yan et al., 2013).

The Three-Dimensional (3D) cell culture system provides a condition resembling naive body tissues, which allows cell-cell and cell-matrix communications (Kim, 2005; Tavakol et al., 2017). Hydrogel scaffolds are widely used in 3D cell culture given the similarity of their structure to the native tissue and provision of biological activities (Tavakol et al., 2015; Tavakol et al., 2019). Both natural and synthetic hydrogels can mimic the properties of extracellular matrix for cell metabolisms (Tavakol et al.,2017; Tibbitt \& Anseth, 2009). In addition to the 3D structure, the hydrogel scaffold plays a conductive role that regulates cell behaviors, such as migration, survival, proliferation, and differentiation (Zheng et al., 2010). Moreover, the advantages of applying conductive polymers to tissue engineering have been demonstrated in cardiac and neural tissue engineering (Ghasemi-Mobarakeh et al., 2011; Qazi et al., 2014). Electrical stimulation influences the survival, differentiation, and proliferation of various stem cells, including embryonic stem cells (Serena et al., 2009), neural stem cells (Åkerud et al., 2001), and bone marrow mesenchymal stem cells (Sun et al., 2009). In addition, the role of electrical stimulation in the differentiation of embryonic stem cells into neuronal cells has been reported (Yamada et al., 2007). This study aims to determine the transdifferentiation capacity of HUC-MSCs toward dopaminergic neurons on Matrigel. 


\section{Materials and Methods}

Human umbilical cord-derived mesenchymal stem cells isolation and culture

At first, the human umbilical cords were obtained, and then HUC-MSCs were isolated and collected in the Hanks' balanced salt solution (HBSS) media. All human umbilical cords were obtained from consenting mothers. The umbilical cords were cut into small pieces and cultured as explants in tissue culture plates in a humidified incubator with $5 \% \mathrm{CO} 2$ at $37^{\circ} \mathrm{C}$. The culture medium was Dulbecco's modified eagle medium (DMEM-F12) supplemented with $15 \%$ fetal bovine serum (FBS, Gibco), $100 \mathrm{U} / \mathrm{mL}$ penicillin, and $60 \mu \mathrm{g} / \mathrm{mL}$ streptomycin (complete medium). Cells at the confluence of $90 \%$ were either sub-cultured or cryopreserved for further application Hour et al., 2020).

\section{Flow cytometry}

The homogeneity of HUC-MSCs was assessed by flow cytometry. Cells were detached and suspended in the phosphate-buffered saline (PBS) to end this. Then, the flow cytometry (FCM, BD FACS Caliber, Becton Dickinson, San Jose, CA, USA) was used to analyze HUCMSCs markers, including CD90 (Cat. No: ab124527, 1/500), CD105 (Cat. No: ab53318, 1/500), and CD73 (Cat. No: ab253267, 1/300), and hematopoietic stem/ progenitor cell marker CD34 (Cat. No: ab78165, 1/300) and CD45 (Cat. No: ab185385, 1/500) (Pirhajati Mahabadi et al., 2015; Simorgh et al., 2019). All antibodies were purchased from Abcam Company.

\section{Adipogenic and osteogenic differentiation}

HUC-MSCs differentiation capacity into adipocytic and osteocytic cells was evaluated. Adipogenic differentiation was induced by culturing HUC-MSCs in a $10 \%$ FBS-supplemented medium and $100 \mathrm{nM}$ dexamethasone (Sigma-Aldrich). Also, the differentiation medium containing $10 \mathrm{nM} \beta$-glycerophosphate, $80 \mu \mathrm{g} / \mathrm{mL}$ ascorbic acid, and $10 \mathrm{nM}$ dexamethasone (Sigma-Aldrich) was applied as the osteogenic differentiation medium. Then, after the 21-day cultures in the above-mentioned conditions, HUC-MSCs were fixed with $4 \%$ paraformaldehyde (PFA, Sigma-Aldrich) and stained with oil red (Sigma-Aldrich) and Alizarin Red S (Merck) to detect adipogenic and osteogenic differentiation, respectively. Plates were photographed using a light microscope equipped with a digital camera. Cells that were cultivated in the basal medium served as the control (Khodaban- deh, Vojdani, Talaei-Khozani, Jaberipour, Hosseini, A., \& Bahmanpour, 2016; Rahimi et al., 2018).

\section{Induction of dopaminergic differentiation}

A 4-step method was used to induce dopaminergic differentiation. At first, cell aggregates (neurosphere) were formed in the neurobasal medium and N2 supplement (Gibco) in 2 days (stage 1). At stage 2, neurospheres were either plated onto Matrigel (BD Biosciences) plate (MP, 3D) or the tissue culture plate (TCP, 2D) as the control. The medium was substituted for the serum-free neurobasal medium with insulin-transferrin-sodium, 50 $\mathrm{ng} / \mathrm{mL}$ basic fibroblast growth factor (bFGF), and $50 \mathrm{ng} /$ $\mathrm{mL}$ EGF for 6 days. At stage 3, for the dopaminergic differentiation, cells were incubated in N2B27 containing $50 \mathrm{ng} / \mathrm{mL}$ bFGF, $100 \mathrm{ng} / \mathrm{mL}$ FGF8b, $250 \mathrm{ng} / \mathrm{mL}$ sonic hedgehog $(\mathrm{SHH})$, and ascorbic acid for 6 days (Alizadeh et al., 2019). To obtain more mature dopaminergic neurons, cell cultivation was kept for the next 6 days in N2B27 in the absence of any growth factors (stage 4) (Simorgh et al., 2019). The induction medium was modified every 2 days. All growth factors in this section were purchased from Sigma-Aldrich.

\section{MTT assay}

Cell viability assessment was conducted based on tetrazolium salt (MTT, 3-[4, 5-Dimethyl-2-thiazolyl]-2, 5-diphenyl-2Htetrazolium bromide) reduction assay at the end of each stage (days 2, 8, 14, and 20). In brief, $5 \times$ 103 cells were seeded onto each well of 96 -well plates. $50 \mu \mathrm{L}$ of $1 \mathrm{mg} / \mathrm{mL}$ MTT solution (Sigma-Aldrich) was added and cells were incubated for $3 \mathrm{~h}$ at $37^{\circ} \mathrm{C}$ in subdued lighting. The media was then removed and replaced with $50 \mu \mathrm{L}$ of $100 \%$ dimethyl sulfoxide (DMSO, SigmaAldrich). Plates were agitated for 5 to $10 \mathrm{~min}$ and the absorbance was measured at $570 \mathrm{~nm}$ using a Cytofluor 4000 plate reader (PerSeptive Biosystems, Framingham, Massachusetts, USA). All experiments were performed in 3 replicate wells (Rafat et al., 2018).

\section{Real-time polymerase chain reaction}

Total cellular RNA was extracted at various differentiation stages by Trizol Reagent (Invitrogen Life Technologies) and reverse-transcribed into cDNA by using a commercial kit (Fermentas) (Karimi et al., 2015). Quantitative real-time RT-PCR was performed on the Corbett apparatus (Qiagen, Germany) using $1 \mu \mathrm{g}$ of cDNA, $10 \mu \mathrm{L}$ of SYBR green, $20 \mu \mathrm{L}$ of deionized distilled water $\left(\mathrm{ddH}_{2} \mathrm{O}\right)$, and $300 \mathrm{nM}$ of forward and reverse primers (Abedini et al., 2019; Mirzaei et al., 
2016). The initial denaturation was performed at $95^{\circ} \mathrm{C}$ for $15 \mathrm{~min}$. It was then followed for 45 cycles by denaturation at $94^{\circ} \mathrm{C}$ for $15 \mathrm{~s}$, annealing at the appropriate temperature for $30 \mathrm{~s}$ (Table 1), and elongation at $72^{\circ} \mathrm{C}$ for $45 \mathrm{~s}$. Primer sequences are provided in Table 1.

\section{Immunocytochemistry}

Cells at different stages were washed and fixed with 4\% paraformaldehyde (PFA) for $15 \mathrm{~min}$. Subsequently, cells were permeabilized with 1\% Triton X-100 (Sigma-Aldrich) for $30 \mathrm{~min}$ at room temperature and then blocked with $2 \%$ BSA (bovine serum albumin, SigmaAldrich) for $45 \mathrm{~min}$. Cells were incubated with Nestin (rabbit polyclonal to Nestin, ab92391, Abcam system, UK), microtubule-associated protein 2 (MAP2, rabbit polyclonal to MAP2, ab32454, Abcam system, UK), and tyrosine hydroxylase (TH, Rabbit polyclonal to tyrosine hydroxylase, ab112, Abcam, UK) for $1 \mathrm{~h}$. PBS cells were washed and incubated with an appropriate secondary antibody (donkey anti-rabbit phycoerythrin, ab7007, Abcam, UK) for $1 \mathrm{~h}$ at $37^{\circ} \mathrm{C}$. After counterstaining with DAPI (Sigma-Aldrich), they were examined under a fluorescent microscope (Nikon, Eclipse-TE600, Japan). The number of immunoreactive cells was determined to estimate the percentage of immunoreactive cells. A random table was utilized to select the fields, and 200 cells were counted (Nasiri et al., 2019; Shaabani et al., 2011).

Determination of dopamine by high-performance liquid chromatography

Dopamine levels were measured using high-performance liquid chromatography (HPLC) at 20 days in vitro (DIV). At the end of the experiment (stage 4), cells were rinsed twice in HBSS for $15 \mathrm{~min}$. The samples were exposed to HBSS supplemented with $56 \mathrm{mM} \mathrm{KCl}$ for $30 \mathrm{~min}$ at $37^{\circ} \mathrm{C}$. Then, the cells were centrifuged at $15000 \mathrm{rpm}$ at $4^{\circ} \mathrm{C}$ for $15 \mathrm{~min}$. Subsequently, the collected supernatants were incubated in $1 \mathrm{~N}$ perchloric acid (PCA; Merck) containing $0.2 \mathrm{~g} / \mathrm{L} \mathrm{Na} 2 \mathrm{~S} 2 \mathrm{O} 5,0.05 \mathrm{~g} / \mathrm{L}$ Na2-EDTA. Samples were injected and immediately detected by HPLC (Data Apex, Petrzilkova, Czech Republic). A monolithic column (Chromolith, 100×4.6 $\mathrm{mm}$ ) was applied for the chromatographic separation (Merck, Germany). The mobile phase consisted of 0.1 M sodium acetate (Sigma), 6\% methanol (Merck), 18 $\mathrm{mg} / \mathrm{mL}$-octyl sodium sulfate (Merck), and $13 \mathrm{mg} / \mathrm{mL}$ EDTA (Sigma) dissolved in Milli-Q-water and adjusted to $\mathrm{pH}=4.1$. Analyses were performed at flow rate and data comparison was conducted with known DA standards. The samples were collected from 3 separate experiments (Aligholi et al., 2014).

\section{Statistical analysis}

One-way analysis of variance (ANOVA) and the Chi-square tests were used for data analysis among the groups. Statistical analysis was performed by the SPSS software, v. 16. The $\mathrm{P}<0.05$ was considered a significant level.

\section{Results}

Characterization of the isolated human umbilical cord-derived mesenchymal stem cells

Mesenchymal stem cells (MSCs) were migrated out from umbilical cord explants to the culture plates. On the seventh day, the fragments of the tissue were removed from the culture plates. The multi-lineage differentiation of HUC-MSCs showed obvious lipid vacuoles and mineralized matrix formation after adipogenic (Figure 1A) and osteogenic (Figure 1B) differentiation, respectively. Additionally, the immunophenotyping of HUC-MSCs (Figure 1C) revealed that they expressed mesenchymal CD markers, namely CD73, CD90, and CD105, although they were negative for hematopoietic CD markers, such as CD34 and CD45 (Figure 1C).

Survival rate of human umbilical cord-derived mesenchymal stem cells

The effect of Matrigel on the viability of HUC-MSCs was investigated using the MTT assay on days 2, 8, 14, and 20 of cell seeding (Figure 2 ). The cell viability percentage between Matrigel (3D) and tissue culture plate (2D) did not show any statistically significant difference.

Differentiation of the human umbilical cordderived mesenchymal stem cells into dopaminergic neurons

Immunocytochemistry staining of the Nestin, MAP2, and TH markers was performed on days 2, 8, and 14 of differentiation (Figure 3). The HUC-MSCs on the Matrigel scaffold and tissue culture plate only expressed Nestin on day 2 of differentiation, with an expression significantly higher $(\mathrm{P}<0.05)$ in cells on the Matrigel scaffold (12.9\%) compared to the tissue culture plate (11.2\%). However, after 8 days, the expression of Nestin in cells on the Matrigel scaffold dropped to a significantly $(\mathrm{P}<0.05)$ lower percentage $(4.3 \%)$ as compared to cells on the tissue culture plate $(7.9 \%)$. The expression of the TH marker on this day remained zero, but the expression of MAP2 was observed in cells of both samples with a significantly higher expression $(\mathrm{P}<0.05)$ on the Matrigel scaffold $(5.6 \%)$ compared to the tissue cul- 

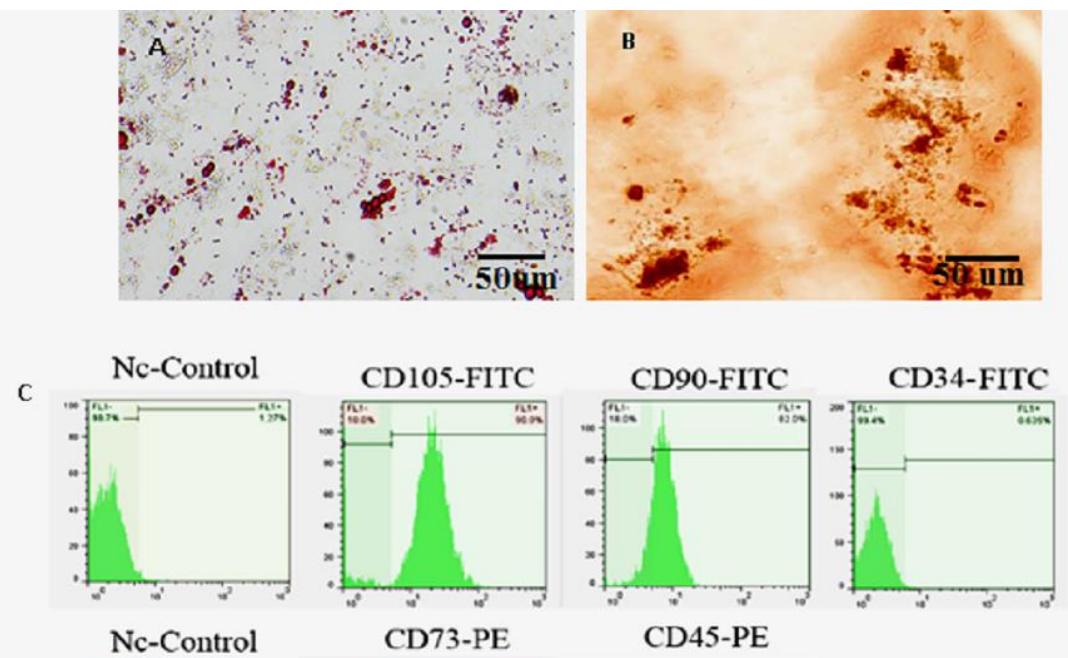

CD73-PE
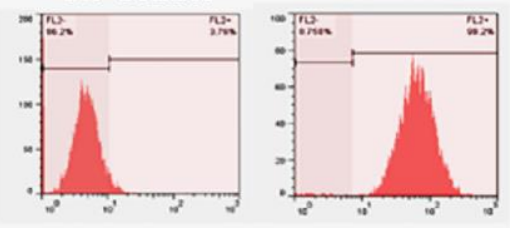

CD45-PE

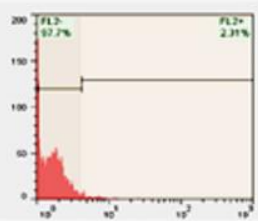

Figure 1. Differentiation of human umbilical cord-derived mesenchymal stem cells into

(A) adipocytes stained by oil red O; (B) osteoblasts stained by Alizarin red S; (C) cytofluorometric results of passage 3 mentioned cells which were positive for CD90, CD73, CD105, and negative to CD34, CD45.

ture plate $(2.1 \%)$. On day 14 of differentiation, cells on both samples expressed all three markers with an almost equal expression of Nestin (2.1\% for tissue culture plate and $2 \%$ for Matrigel scaffold). The MAP2 and TH expression level for cells cultured on the Matrigel scaffold was higher than the expression of the tissue culture plate, but the difference reached a significant level $(\mathrm{P}<0.05)$ for the TH marker, ( $6 \%$ on the Matrigel scaffold vs $2.4 \%$ on tissue culture plate). Furthermore, HUC-MSCs on the Matrigel scaffold demonstrated their capability to express Nestin, MAP2, and TH (Figure 4).

MTT

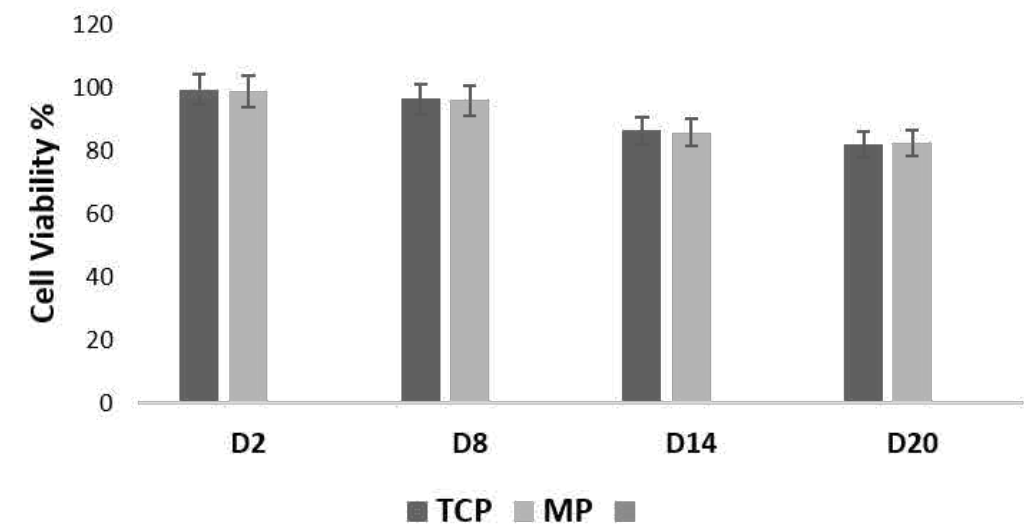

NEUR SCIENCE

Figure 2. Viability Percentage of Human Umbilical Cord-Derived Mesenchymal Stem Cells on Matrigel Plates and Tissue Culture Plate Measured by the MTT Assay 2, 8, 14, and 20 Days After the Cell Seeding

There were no statistically significant differences between Matrigel plates and tissue culture plates at all time points. Error bars represent the standard deviation. 
Table 1. Real-time polymerase chain reaction primer sequences

\begin{tabular}{|c|c|c|c|}
\hline Row & Gene & Sequence $5^{\prime}$ to $3^{\prime}$ & Annealing Temperature $\left({ }^{\circ} \mathrm{C}\right)$ \\
\hline 1 & $\mathrm{TH}$ & $\begin{array}{l}\text { F: CGGATGAGGAAATTGAGAAGCTG } \\
\text { R: AGACAGGCAGTGCAGGAGCTC }\end{array}$ & 61 \\
\hline 2 & DAT & $\begin{array}{l}\text { F: CCCACTACGGAGCCTACATCTTC } \\
\text { R: CGTAGGCCAGTTTCTCTCGAAAG }\end{array}$ & 60 \\
\hline 3 & NURR1 & $\begin{array}{l}\text { F: CAAATAAAAACTGCCCAGTGGACAAG } \\
\text { R: TGTCTGTGCGAACCACTTCTTTG }\end{array}$ & 62 \\
\hline 4 & PITX3 & $\begin{array}{l}\text { F: GCTCCCCAGAGGACGGTTC } \\
\text { R: TTCTTGAACCACACCCGCAC }\end{array}$ & 60 \\
\hline 5 & LMX1A & $\begin{array}{l}\text { F: TCGAATCCTGCACGTGTGACTAC } \\
\text { R: ATCTCGAGAATACGGTCGTACG }\end{array}$ & 62 \\
\hline 6 & AADC & $\begin{array}{l}\text { F: CTCCCGGCTGCCTTTTTTCA } \\
\text { R: ATCACTCCTCCCCCTTCTCC }\end{array}$ & 60 \\
\hline 7 & NESTIN & $\begin{array}{l}\text { F: AAAGTTCCAGCTGGCTGTGG } \\
\text { R: TCCAGCTTGGGGTCCTGAAA }\end{array}$ & 55 \\
\hline 8 & Oct4 & $\begin{array}{l}\text { F: TCAGGTTGGACTGGGCCTAGT } \\
\text { R: GGAGGTTCCCTCTGAGTTGCTT }\end{array}$ & 60 \\
\hline 9 & SOX2 & $\begin{array}{l}\text { F: AACCAGAAAAACAGCCCGGA } \\
\text { R: AACCAGAAAAACAGCCCGGA }\end{array}$ & 57 \\
\hline 10 & GAPDH & $\begin{array}{l}\text { F: AGCCACATCGCTCAGACACC } \\
\text { R: GTACTCAGCGGCCAGCATCG }\end{array}$ & 61 \\
\hline
\end{tabular}

NEUR:SCIENCE

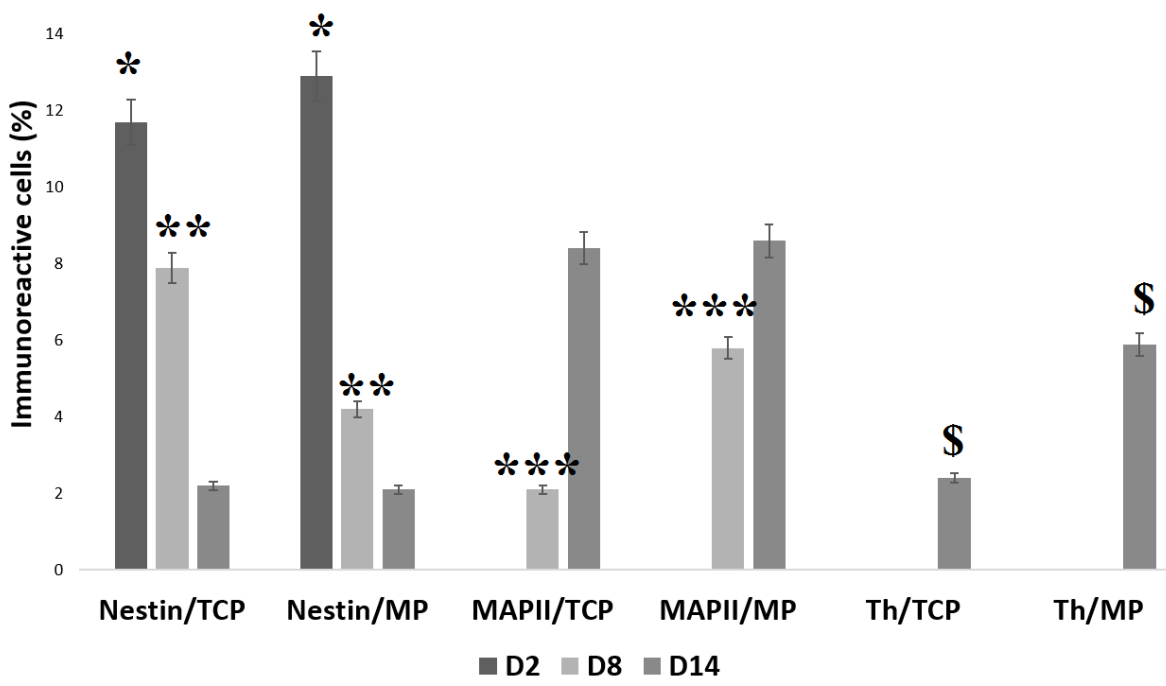

NEUR:SCIENCE

Figure 3. Histogram of the Percentage of Human Umbilical Cord-Derived Mesenchymal Stem Cells Differentiated in Matrigel Culture Plate and Tissue Culture Plate on days 2, 8, and 14

Values are expressed as mean \pm standard deviation $(n=3)$. * indicates the statistical significance of Nestin expression between Matrigel culture plate and tissue culture plate on day $2(\mathrm{P}<0.05) .{ }^{* *}$ indicates the statistical significance of Nestin expression between Matrigel culture plate and tissue culture plate on day $8(\mathrm{P}<0.01) .{ }^{* * *}$ indicates the statistical significance of MAP2 expression between the Matrigel culture plate and tissue culture plate on day $8(\mathrm{P}<0.001)$. $\$$ indicates the statistical significance of TH expression between the Matrigel culture plate and tissue culture plate on day $14(\mathrm{P}<0.05)$. 


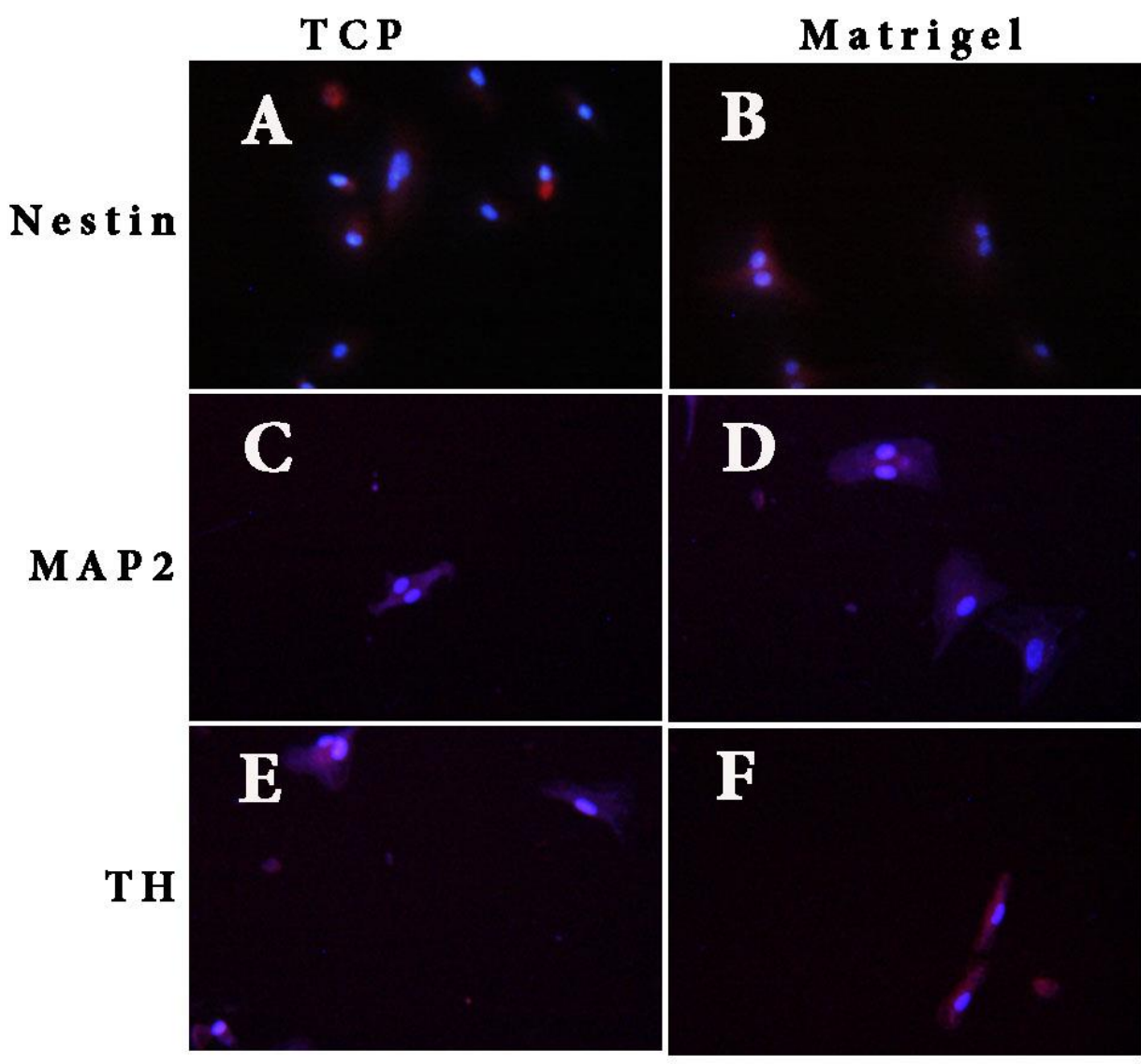

NEUR SCIENCE

Figure 4. Immunofluorescence Results of Human Umbilical Cord-Derived Mesenchymal Stem Cells Induced in Matrigel and Tissue Culture Plate

Notes: (A and B): Nestin-positive cells in tissue culture plate and Matrigel, respectively. (C and D): MAP2-positive cells in tissue culture plate and Matrigel, respectively. (E and F): TH-positive cells in tissue culture plate and Matrigel, respectively (counterstained with DAPI). (Scale bars, A, B, C, D, and $E=50 \mu \mathrm{m}$ and $\mathrm{F}=20 \mu \mathrm{m}$ ).

Dopaminergic genes expression after dopaminergic induction of the human umbilical cordderived mesenchymal stem cells

The q-PCR analysis of Oct4, Sox2, Nestin, Nurr1, PITX3, LMX1A, TH, AADC, and DAT revealed that the expression of Nestin and Oct4 on Matrigel scaffoldseeded cells took a downturn from day 2 to day 20. On the other hand, the expression of markers of Nurr1, PITX3, LMX1A, TH, AADC, and DAT increased considerably from day 2 to day 20. The expression of Sox 2 dropped from day 2 to day 14, but on day 20, it recorded a higher expression compared to day 14 (Figure 5).

Quantification of dopamine release from differentiated human umbilical cord-derived mesenchymal stem cells

To determine whether HUC-MSCs differentiated neurons can release dopamine, TH levels were measured us- ing HPLC (Figure 6). The dopamine amount from the Matrigel and tissue-culture-plate-seeded HUC-MSCs were $223.09 \pm 22.08715 \mathrm{pg} / \mathrm{mL}$ and $208.59 \pm 12.05329$ $\mathrm{pg} / \mathrm{mL}$, respectively. Although dopamine release was slightly higher on Matrigel cultured cells, the difference was not statistically significant.

\section{Discussion}

As expected, HUC-MSCs expressed prominent mesenchymal markers but lacked the endothelial and hematopoietic CD markers. Directing HUC-MSCs toward osteogenic and adipogenic lineages demonstrated their multi-lineage differentiation capacity. The viability of HUC-MSCs was also investigated through in vitro cultivation on the scaffold after 2, 8, 14, and 20 days. The cells cultured on both tissue culture plates and Matrigel scaffold exhibited excellent viability. In line with other studies, it demonstrates the favorable 


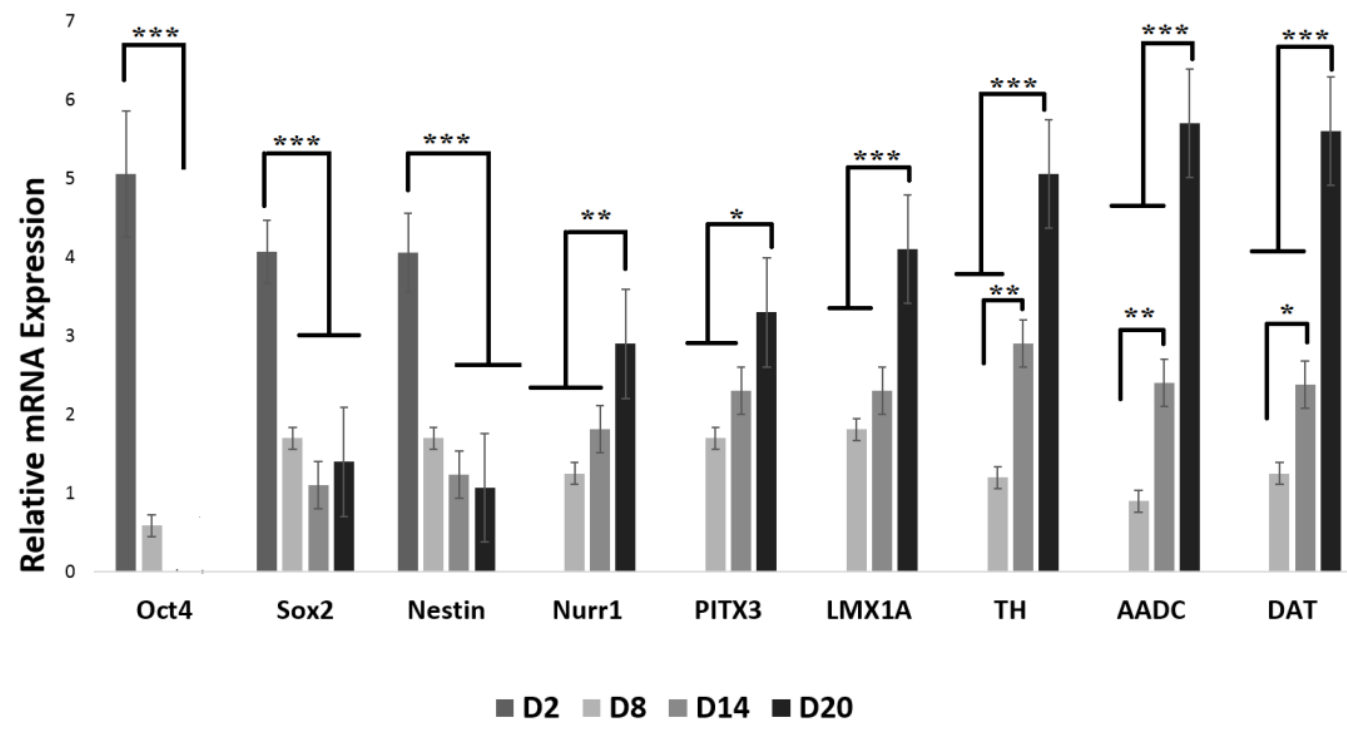

NEUR:SCIENCE

Figure 5. Real-Time Polymerase Chain Reaction Results for Neural and Dopaminergic Specific Genes During the Induction of Human Umbilical Cord-Derived Mesenchymal Stem Cells for Different Days on Matrigel Scaffold

$\mathrm{n}=3$ biological samples, mean \pm standard deviation; ${ }^{* * *} \mathrm{P}<0.001,{ }^{* *} \mathrm{P}<0.01,{ }^{*} \mathrm{P}<0.05$.

substrate provided by this scaffold for HUC-MSCs (Massumi et al., 2011; Uemura, Refaat et al., 2010).

Up to date, different cell types have been applied for cell transplantation in neurodegenerative diseases. MSCs which are mostly obtained from the bone marrow, adipose tissue, and umbilical cord are endowed with greater attention (Bojnordi et al., 2013; Sadan et al., 2009; Yousefi, Sanooghi et al., 2017). There are also several studies demonstrating their effectiveness in animal models of Parkinson disease (Braun \& Jessberger, 2014; Trzaska et al., 2007). MSCs obtained from the umbilical cord are an ideal source of cell transplantation due to features, such as easy harvest, high proliferation rate, and low immunogenicity
(Hamidabadi et al., 2019; Liu et al., 2014; van Heesbeen et al., 2013).

The cytofluorometric analysis of neural markers of Nestin and MAP2, as well as major dopaminergic cell markers of $\mathrm{TH}$, revealed that $\mathrm{TH}$ expression in cells cultured on Matrigel increased from day 2 to day 14 compared to cells cultured on a tissue culture plate. It has been shown that $\mathrm{TH}$ expression is higher in the mature dopaminergic neurons (Zavala-Arcos et al., 2013). The down-regulation of the Nestin gene also demonstrated the effective differentiation of HUCMSCs toward neurons. The up-regulation of the TH gene and down-regulation of the Nestin gene was also confirmed by real-time PCR analysis. Uemura et al. (2010), Mojaverrostami et al. (2018) reported that

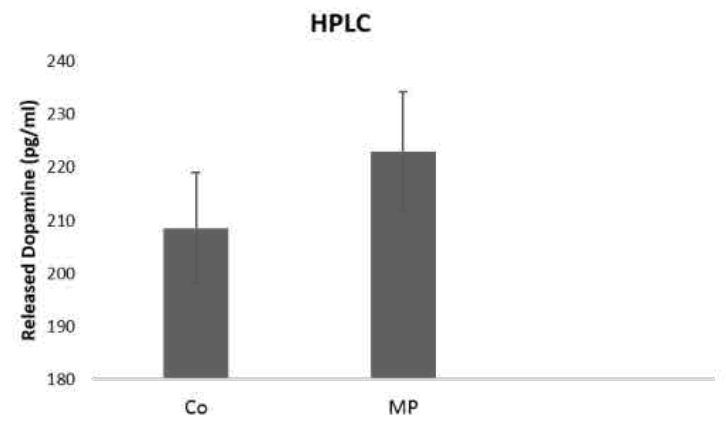

NEUR SCIENCE

Figure 6. Amount of Dopamine Released From Dopaminergic Neurons Differentiated Human Umbilical Cord-Derived Mesenchymal Stem Cells in Matrigel Plates and Control Groups

Notes: Values are expressed as Mean \pm Standard Deviation $(n=3)$. 
grafting neural precursor cells with Matrigel scaffold in mice could enhance cell survival and differentiation, which reflects the positive effect of Matrigel on cell transplantation in neurological disorders.

We combined HUC-MSCs with Matrigel, as a scaffold material, promoting cell attachment, proliferation, and differentiation (Jin et al., 2010; Vanacker et al., 2012). Matrigel is a soluble extract of tumor-cell basement membrane that forms a $3 \mathrm{D}$ gel at $37^{\circ} \mathrm{C}$ (Park et al., 2012). Mainly composed of $60 \%$ laminin, $30 \%$ type IV collagen, and $8 \%$ entactin, it has been demonstrated to contribute to the differentiation of different cell types (Engbring \& Kleinman, 2003; Moreno et al., 2015; Sypecka et al., 2009).

To the best of our knowledge, there are no reports regarding the establishment of HUC-MSCs-seeded Matrigel scaffold for the treatment of Parkinson disease. We hypothesized that the positive effects of Matrigel on neural cells originate from its chemical composition, which is chiefly composed of laminin and type IV collagen. Laminin is an ECM molecule enhancing neural proliferation and differentiation via laminin/ $\alpha 6 \beta 1$ integrin signaling (Ma et al., 2008). On the other hand, type IV collagen can influence neural cell migration and morphogenesis via type IV collagen/BMP-4 signaling (Reiriz et al., 1999). It has been shown that Matrigel provides a suitable scaffold for the survival and differentiation of embryonic stem cell-derived neural precursor cells into TH-positive dopaminergic neurons (Uemura et al., 2010).

Ni et al. (2013) reported that cell proliferation was enhanced in Matrigel-derived 3D culture. This study suggests that Matrigel provides an appropriate condition for cell survival and growth (Ni et al., 2013). Further, it has been documented that Matrigel could assist the differentiation of MSCs into other linage cells. Matrigel boosted osteoblastic differentiation of human marrow-derived mesenchymal stem cells (Baghaban, Bagheri, \& Zomorodian, 2010)

Matrigel is a natural Extracellular Matrices (ECM) that is both biocompatible and biodegradable. It appears that Matrigel improves cell survival and differentiation efficiently under in vitro and in vivo conditions. Similar to collagen and laminin, Matrigel can provide an appropriate microenvironment for cell attachment, growth, and ECM deposition.

Wnag et al. (2020) showed that Matrigel was a promising scaffold material for cell transplantation in the spi- nal cord injury model (Wang, et al., 2020). The Matrigel with neural stem cells could improve neuronal regeneration and functional recovery (Wang, et al., 2020). The combination of Matrigel with MSCs or embryo-derived neural stem cells in canine models has promoted neuronal regeneration (Park et al., 2012). The probable mechanisms for the supportive effect of Matrigel may associate with the liberation of dying cells, increased cell population, and reduced inflammatory response. In addition, growth factors of Matrigel, such as FGF-2, and EGF promote cell proliferation.

\section{Conclusion}

In this study, the effects of the Matrigel scaffold on the differentiation of HUC-MSCs into dopaminergic neurons were investigated. The dopaminergic differentiation of HUC-MSCs on Matrigel was higher than on cells cultured on a tissue culture plate. However, dopamine release was observed in both Matrigel and control groups. The findings demonstrated the great potential of Matrigel as a favorable scaffold for the differentiation of HUC-MSCs in stem cell therapy to treat neurodegenerative disorders, such as Parkinson disease.

\section{Ethical Considerations}

\section{Compliance with ethical guidelines}

All applicable national and international guidelines for animal care and use were observed.

\section{Funding}

This research was supported by the research project (No.: 1396.90), funded by Ilam University of Medical Sciences University (IR.MEDILAM.REC.1396.90).

\section{Authors' contributions}

Conceptualization and supervision: Hatef Ghasemi Hamidabadi; Methodology: Maryam Nazm Bojnordi; Investigation, Writing-original draft, and Writing-review \& editing: All authors; Data collection: Rafieh Alizadeh; Data analysis: Ali Niapour and Azim Hedayatpour; Project administration, and Funding acquisition: Ardeshir Moayeri.

\section{Conflict of interest}

The authors declared no conflict of interest. 


\section{Acknowledgments}

We especially thank Anatomy \& Cell Biology Department of Mazandaran University of Medical Science for providing cell culture lab.

\section{References}

Abedini, P., Fattahi, A., Agah, S., Talebi, A., Beygi, A. H., \& Amini, S. M., et al. (2019). Expression analysis of circulating plasma long noncoding RNAs in colorectal cancer: The relevance of lncRNAs ATB and CCAT1 as potential clinical hallmarks. Journal of Cellular Physiology, 234(12), 22028-22033. [PMID]

Akerud, P., Canals, J. M., Snyder, E. Y., \& Arenas, E. (2001). Neuroprotection through the delivery of glial cell line-derived neurotrophic factor by neural stem cells in a mouse model of Parkinson>s disease. The Journal of Neuroscience: The Official Journal of the Society for Neuroscience, 21(20), 8108-8118. [PMID] [PMCID]

Aligholi, H., Hassanzadeh, G., Azari, H., Rezayat, S. M., Mehr, S. E., \& Akbari, M., et al. (2014). A new and safe method for stereotactically harvesting neural stem/progenitor cells from the adult rat subventricular zone. Journal of Neuroscience Methods, 225, 81-89. [PMID]

Alizadeh, R., Mehrabi, S., \& Hadjighassem, M. (2014). Cell therapy in parkinson's disease. Archives Neuroscience, 1(2), 43-50. [DOI:10.5812/archneurosci.10279]

Alizadeh, R., Ramezanpour, F., Mohammadi, A., Eftekharzadeh, M., Simorgh, S., \& Kazemiha, M., et al. (2019). Differentiation of human olfactory system-derived stem cells into dopaminergic neuron-like cells: A comparison between olfactory bulb and mucosa as two sources of stem cells. Journal of Cellular Biochemistry, 120(12), 19712-19720. [DOI:10.1002/jcb.29277]

Allam, M. F., Del Castillo, A. S., \& Navajas, R. F. (2005).Parkinson's disease risk factors: Genetic, environmental, or both? Neurological Research, 27(2), 206-208. [PMID]

Baghaban, E. M., Bagheri, F., \& Zomorodian, E. (2010). Matrigel enhances in vitro bone differentiation of human marrow-derived mesenchymal stem cells. Iranian Journal of Basic Medical Sciences, 13(1), 187-194. [Link]

Bojnordi, M. N., Ebrahimi-Barough, S., Vojoudi, E., \& Hamidabadi, H. G. (2018). Silk nanofibrous electrospun scaffold enhances differentiation of embryonic stem like cells derived from testis in to mature neuron. Journal of Biomedical Materials Research Part A, 106(10), 2662-2669. [PMID]

Nazm Bojnordi, M., Movahedin, M., Tiraihi, T., \& Javan, M. (2013). Alteration in genes expression patterns during in vitro differentiation of mouse spermatogonial cells into neuroepithelial-like cells. Cytotechnology, 65(1), 97-104. [PMID] [PMCID]

Bongso, A., \& Fong, C. Y. (2013). The therapeutic potential, challenges and future clinical directions of stem cells from the Wharton's jelly of the human umbilical cord. Stem Cell Reviews and Reports, 9(2), 226-240. [PMID]
Braun, S. M., \& Jessberger, S. (2014). Adult neurogenesis: Mechanisms and functional significance. Development 141(10), 1983-1986. [PMID]

Cao, N., Liao, T., Liu, J., Fan, Z., Zeng, Q., \& Zhou, J., et al. (2017). Clinical-grade human umbilical cord-derived mesenchymal stem cells reverse cognitive aging via improving synaptic plasticity and endogenous neurogenesis. Cell Death $\mathcal{E}$ Disease, 8(8), e2996. [PMID] [PMCID]

Chu, T., Zhou, H., Wang, T., Lu, L., Li, F., \& Liu, B., et al. (2015). In vitro characteristics of valproic acid and all-transretinoic acid and their combined use in promoting neuronal differentiation while suppressing astrocytic differentiation in neural stem cells. Brain Research, 1596, 31-47. [PMID]

Engbring, J. A., \& Kleinman, H. K. (2003). The basement membrane matrix in malignancy. The Journal of Pathology, 200(4), 465-470. [PMID]

Ghasemi-Mobarakeh, L., Prabhakaran, M. P., Morshed, M., Nasr-Esfahani, M. H., Baharvand, H., \& Kiani, S., et al. (2011). Application of conductive polymers, scaffolds and electrical stimulation for nerve tissue engineering. Journal of Tissue Engineering and Regenerative Medicine, 5(4), e17-e35. [PMID]

Ghasemi Hamidabadi, H., Nazm Bojnordi, M., Rezaei, N., \& Soleimani, S. (2019). Evaluation of differential gene expression during transdifferentiation of bone marrow stromal cells to glial phenotype in the presence of cerebrospinal fluid. Avicenna Journal of Medical Biotechnology, 11(1), 28-34. [PMID]

Haratizadeh, S., Nazm Bojnordi, M., Niapour, A., Bakhtiari, M., \& Ghasemi Hamidabadi, H. (2016). [Improvement of neuroglial differentiation from human dental pulp stem cells using CSF (Persian)]. Journal of Mazandaran University of Medical Sciences, 26(140), 1-14. [Link]

Hour, F. Q., Moghadam, A. J., Shakeri-Zadeh, A., Bakhtiyari, M., Shabani, R., \& Mehdizadeh, M. (2020). Magnetic targeted delivery of the SPIONs-labeled mesenchymal stem cells derived from human Wharton's jelly in Alzheimer's rat models. Journal of Controlled Release, 321, 430-441. [PMID]

Jin, K., Mao, X., Xie, L., Galvan, V., Lai, B., \& Wang, Y., et al. (2010). Transplantation of human neural precursor cells in Matrigel scaffolding improves outcome from focal cerebral ischemia after delayed postischemic treatment in rats. Journal of Cerebral Blood Flow \& Metabolism, 30(3), 534-544. [PMID] [PMCID]

Karimi, A., Majidzadeh-A, K., Madjd, Z., Akbari, A., Habibi, L., \& Akrami, S. M. (2015). Effect of copper sulfate on expression of endogenous L1 retrotransposons in HepG2 cells (hepatocellular carcinoma). Biological Trace Element Research, 165(2), 131-134. [PMID]

Kawasaki, H., Mizuseki, K., Nishikawa, S., Kaneko, S., Kuwana, Y., \& Nakanishi, S., et al. (2000). Induction of midbrain dopaminergic neurons from ES cells by stromal cellderived inducing activity. Neuron, 28(1), 31-40. [PMID]

Khodabandeh, Z., Vojdani, Z., Talaei-Khozani, T., Jaberipour, M., Hosseini, A., \& Bahmanpour, S. (2016). Comparison of the expression of hepatic genes by human Wharton's Jelly Mesenchymal stem cells cultured in 2D and 3D Collagen culture systems. Iranian Journal of Medical Sciences, 41(1), 28-36. [PMID] 
Kim, J. B. (2005). Three-dimensional tissue culture models in cancer biology. Seminars in Cancer Biology, 15(5), 365-377. [PMID]

Koh, S. H., Kim, K. S., Choi, M. R., Jung, K. H., Park, K. S., \& Chai, Y. G., et al. (2008). Implantation of human umbilical cord-derived mesenchymal stem cells as a neuroprotective therapy for ischemic stroke in rats. Brain Research, 1229, 233 248. [DOI:10.1016/j.brainres.2008.06.087] [PMID]

Kriks, S., Shim, J. W., Piao, J., Ganat, Y. M., Wakeman, D. R. \& Xie, Z., et al. (2011). Dopamine neurons derived from human ES cells efficiently engraft in animal models of Parkinson's disease. Nature, 480(7378), 547-551. [PMID]

Liu, L., Yu, Y., Hou, Y., Chai, J., Duan, H., \& Chu, W., et al. (2014). Human umbilical cord mesenchymal stem cells transplantation promotes cutaneous wound healing of severe burned rats. PloS One, 9(2), e88348. [PMID] [PMCID]

Lu, C., Zhang, J., Shi, X., Miao, S., Bi, L., \& Zhang, S., et al.(2014). Neuroprotective effects of tetramethylpyrazine against dopaminergic neuron injury in a rat model of Parkinson's disease induced by MPTP. International Journal of Biological Sciences, 10(4), 350-357. [PMID] [PMCID]

Ma, W., Tavakoli, T., Derby, E., Serebryakova, Y., Rao, M. S., \& Mattson, M. P. (2008). Cell-extracellular matrix interactions regulate neural differentiation of human embryonic stem cells. BMC Developmental Biology, 8, 90. [PMID] [PMCID]

Massumi, M., Abasi, M., Babaloo, H., Terraf, P., Safi, M., \& Saeed, M., et al. (2012). The effect of topography on differentiation fates of matrigel-coated mouse embryonic stem cells cultured on PLGA nanofibrous scaffolds. Tissue Engineering Part A, 18(5-6), 609-620. [PMID] [PMCID]

Mehraein, F., Sarbishegi, M., \& Golipoor, Z. (2016). Different effects of olive leaf extract on antioxidant enzyme activities in midbrain and dopaminergic neurons of Substantia Nigra in young and old rats. Histology and Histopathology, 31(4), 425-431. [PMID]

Mirzaei, A., Madjd, Z., Kadijani, A. A., Tavakoli-Yaraki, M., Modarresi, M. H., \& Verdi, J., et al. (2016). Evaluation of circulating cellular DCLK1 protein, as the most promising colorectal cancer stem cell marker, using immunoassay based methods. Cancer Biomarkers, 17(3), 301-311. [PMID]

Mojaverrostami, S., Bojnordi, M. N., Ghasemi-Kasman, M. Ebrahimzadeh, M. A., \& Hamidabadi, H. G. (2018). A review of herbal therapy in multiple sclerosis. Advanced Pharmaceutical Bulletin, 8(4), 575-590. [PMID] [PMCID]

Moreno, E. L., Hachi, S., Hemmer, K., Trietsch, S. J., Baumu ratov, A. S., \& Hankemeier, T., et al. (2015). Differentiation of neuroepithelial stem cells into functional dopaminergic neurons in 3D microfluidic cell culture. Lab on a Chip, 15(11), 2419-2428. [PMID]

Nasiri, E., Alizadeh, A., Roushandeh, A. M., Gazor, R., Hashemi-Firouzi, N., \& Golipoor, Z. (2019). Melatonin-pretreated adipose-derived mesenchymal stem cells efficeintly improved learning, memory, and cognition in an animal model of Alzheimer's disease. Metabolic Brain Disease, 34(4), 1131-1143. [PMID]

Ni, N., Hu, Y., Ren, H., Luo, C., Li, P., \& Wan, J. B., et al. (2013). Selfassembling peptide nanofiber scaffolds enhance dopaminergic differentiation of mouse pluripotent stem cells in 3-dimensional culture. PLoS One, 8(12), e84504. [PMID] [PMCID]
Nutt, J. G., \& Wooten, G. F. (2005). Clinical practice. Diagnosis and initial management of Parkinson's disease. The New England Journal of Medicine, 353(10), 1021-1027. [PMID]

Paldino, E., Cenciarelli, C., Giampaolo, A., Milazzo, L., Pescatori, M., \& Hassan, H. J., et al. (2014). Induction of dopaminergic neurons from human Wharton's jelly mesenchymal stem cell by forskolin. Journal of Cellular Physiology, 229(2), 232-244. [PMID]

Park, S. S., Lee, Y. J., Lee, S. H., Lee, D., Choi, K., \& Kim, W H., et al. (2012). Functional recovery after spinal cord injury in dogs treated with a combination of Matrigel and neural-induced adipose-derived mesenchymal Stem cells. Cytotherapy, 14(5), 584-597. [PMID]

Pirhajati Mahabadi, V., Movahedin, M., Semnanian, S., Mirnajafi-Zadeh, J., \& Faizi, M. (2015). In vitro differentiation of neural stem cells into noradrenergic-like cells. International Journal of Molecular and Cellular Medicine, 4(1), 22-31. [PMID]

Politis, M., \& Lindvall, O. (2012). Clinical application of stem cell therapy in Parkinson's disease. BMC Medicine, 10(1), 1. [PMID] [PMCID]

Qazi, T. H., Rai, R., Dippold, D., Roether, J. E., Schubert, D. W., \& Rosellini, E., et al. (2014). Development and characterization of novel electrically conductive PANI-PGS composites for cardiac tissue engineering applications. Acta Biomaterialia, 10(6), 2434-2445. [PMID]

Rafat, A., Mohammadi Roushandeh, A., Alizadeh, A., Hashemi-Firouzi, N., \& Golipoor, Z. (2019). Comparison of the melatonin preconditioning efficacy between bone marrow and adipose-derived mesenchymal stem cells. Cell Journal (Yakhteh), 20(4), 450-458. [PMID]

Rahimi, A., Amiri, I., Roushandeh, A. M., Choshali, Z. G., Alizadeh, Z., \& Artimani, T., et al. (2018). Sublethal concentration of $\mathrm{H}_{2} \mathrm{O}_{2}$ enhances the protective effect of mesenchymal stem cells in rat model of spinal cord injury. Biotechnology Letters, 40(3), 609-615. [PMID]

Reiriz, J., Espejo, M., Ventura, F., Ambrosio, S., \& Alberch, J. (1999). Bone morphogenetic protein-2 promotes dissociated effects on the number and differentiation of cultured ventral mesencephalic dopaminergic neurons. Journal of Neurobiology, 38(2), 161-170. [PMID]

Sadan, O., Melamed, E., \& Offen, D. (2009). Bone-marrowderived mesenchymal stem cell therapy for neurodegenerative diseases. Expert Opinion on Biological Therapy, 9(12) 1487-1497. [PMID]

Serena, E., Figallo, E., Tandon, N., Cannizzaro, C., Gerecht, S., \& Elvassore, N., et al. (2009). Electrical stimulation of human embryonic stem cells: Cardiac differentiation and the generation of reactive oxygen species. Experimental Cell Research, 315(20), 3611-3619. [PMID] [PMCID]

Shaabani, R., Jahanshahi, M., Nowrouzian, M., Sadeghi, Y., \& Azami, N. (2011). Effect of morphine based CPP on the hippocampal astrocytes of male Wistar rats. Asian Journal of Cell Biology, 6(3), 89-96. [DOI:10.3923/ajcb.2011.89.96]

Simorgh, S., Alizadeh, R., Eftekharzadeh, M., Haramshahi, S., Milan, P. B., \& Doshmanziari, M., et al. (2019). Olfactory mucosa stem cells: An available candidate for the treatment of the Parkinson's disease. Journal of Cellular Physiology, 234(12), 23763-23773. [PMID] 
Sun, L. Y., Hsieh, D. K., Yu, T. C., Chiu, H. T., Lu, S. F., \& Luo, G. H., et al. (2009). Effect of pulsed electromagnetic field on the proliferation and differentiation potential of human bone marrow mesenchymal stem cells. Bioelectromagnetics, 30(4), 251-260. [PMID]

Sypecka, J., Dragun-Szymczak, P., Zalewska, T., \& DomańskaJanik, K. (2009). Laminin promotes oligogliogenesis and increases MMPs activity in human neural stem cells of HUCB-NSC line. Acta Neurobiologiae Experimentalis, 69(1), 37-45. [PMID]

Tanna, T., \& Sachan, V. (2014). Mesenchymal stem cells: Potential in treatment of neurodegenerative diseases. Current Stem Cell Research \& Therapy, 9(6), 513-521. [PMID]

Tavakol, S., Hoveizi, E., Tavakol, B., Azedi, F., Ebrahimi-Barough, S., \& Keyhanvar, P., et al. (2019). Small molecule of sphingosine as a rescue of dopaminergic cells: A cell therapy approach in neurodegenerative diseases therapeutics. Journal of Cellular Physiology, 234(7), 11401-11410. [PMID]

Tavakol, S., Modarres Mousavi, S. M., Massumi, M., Amani, A., Rezayat, S. M., \& Ai, J. (2015). The effect of Noggin supplementation in Matrigel nanofiber-based cell culture system for derivation of neural-like cells from human endometrial-derived stromal cells. Journal of Biomedical Materials Research Part A, 103(1), 1-7. [PMID]

Tavakol, S., Mousavi, S. M. M., Tavakol, B., Hoveizi, E., Ai, J., \& Sorkhabadi, S. M. R. (2017). Mechano-transduction signals derived from self-assembling peptide nanofibers containing long motif of laminin influence neurogenesis in invitro and in-vivo. Molecular Neurobiology, 54(4), 2483-2496. [DOI:10.1007/s12035-016-9836-z]

Tavakol, S., Musavi, S., Tavakol, B., Hoveizi, E., Ai, J., \& Rezayat, S. M. (2017). Noggin along with a self-assembling peptide nanofiber containing long motif of laminin induces tyrosine hydroxylase gene expression. Molecular Neurobiology, 54(6), 4609-4616. [PMID]

Tavakol, S., Rasoulian, B., Ramezani, F., Hoveizi, E., Tavakol, B., \& Rezayat, S. M. (2019). Core and biological motif of selfassembling peptide nanofiber induce a stronger electrostatic interaction than BMP2 with BMP2 receptor 1A. Materials Science \& Engineering. C, Materials for Biological Applications, 101, 148-158. [PMID]

Tibbitt, M. W., \& Anseth, K. S. (2009). Hydrogels as extracellular matrix mimics for 3D cell culture. Biotechnology and Bioengineering, 103(4), 655-663. [PMID] [PMCID]

Trzaska, K. A., Kuzhikandathil, E. V., \& Rameshwar, P. (2007). Specification of a dopaminergic phenotype from adult human mesenchymal stem cells. Stem Cells, 25(11), 2797-2808. [PMID]

Uemura, M., Refaat, M. M., Shinoyama, M., Hayashi, H., Hashimoto, N., \& Takahashi, J. (2010). Matrigel supports survival and neuronal differentiation of grafted embryonic stem cell-derived neural precursor cells. Journal of Neuroscience Research, 88(3), 542-551. [PMID]

van Heesbeen, H. J., Mesman, S., Veenvliet, J. V., \& Smidt, M. P. (2013) Epigenetic mechanisms in the development and maintenance of dopaminergic neurons. Development 140(6), 1159-1169. [PMID]
Vanacker, J., Luyckx, V., Dolmans, M. M., Des Rieux, A., Jaeger, J., \& Van Langendonckt, A., et al. (2012). Transplantation of an alginate-matrigel matrix containing isolated ovarian cells: first step in developing a biodegradable scaffold to transplant isolated preantral follicles and ovarian cells. Biomaterials, 33(26), 6079-6085. [PMID]

Wang, J., Chu, R., Ni, N., \& Nan, G. (2020).The effect of Matrigel as scaffold material for neural stem cell transplantation for treating spinal cord injury. Scientific Reports, 10(1), 2576. [PMID] [PMCID]

Wang, J., Wang, X., Sun, Z., Wang, X., Yang, H., \& Shi, S., et al. (2010). Stem cells from human-exfoliated deciduous teeth can differentiate into dopaminergic neuron-like cells. Stem Cells and Development, 19(9), 1375-1383. [PMID] [PMCID]

Yamada, M., Tanemura, K., Okada, S., Iwanami, A., Nakamura, M., \& Mizuno, H., et al. (2007). Electrical stimulation modulates fate determination of differentiating embryonic stem cells. Stem Cells, 25(3), 562-570. [PMID]

Yan, M., Sun, M., Zhou, Y., Wang, W., He, Z., \& Tang, D., et al. (2013). Conversion of human umbilical cord mesenchymal stem cells in Wharton's jelly to dopamine neurons mediated by the Lmx1a and neurturin in vitro: Potential therapeutic application for Parkinson's disease in a rhesus monkey model. PloS One, 8(5), e64000. [PMID]

Yang, D., Zhang, Z. J., Oldenburg, M., Ayala, M., \& Zhang, S. C. (2008). Human embryonic stem cell-derived dopaminergic neurons reverse functional deficit in parkinsonian rats. Stem Cells, 26(1), 55-63. [PMID] [PMCID]

Yousefi, B., Sanooghi, D., Faghihi, F., Joghataei, M. T., \& Latifi, N. (2017). Evaluation of motor neuron differentiation potential of human umbilical cord blood-derived mesenchymal stem cells, in vitro. Journal of Chemical Neuroanatomy, 81, 18-26. [PMID]

Zavala-Arcos, J., Gonzalez-Garza, M. T., Gutierrez-Alcala, J., Martinez, H. R., \& Moreno-Cuevas, J. E. (2013). Direct pre-differentiation of rat mesenchymal stem cells into dopaminergic cells. Stem Cell Discovery, 3(2), 133-138. [DOI:10.4236/scd.2013.32018]

Zheng, L., Fan, H. S., Sun, J., Chen, X. N., Wang, G., \& Zhang, L., et al. (2010). Chondrogenic differentiation of mesenchymal stem cells induced by collagen-based hydrogel: An in vivo study. Journal of Biomedical Materials Research Part A, 93(2), 783-792. [PMID] 